\title{
PLANNING AND INITIATING VIRTUAL COLLABORATIVE NETWORKS FOR 63 SMES IN RURAL AREAS - AN EXAMPLE FROM THE FINNISH ARCHIPELAGO
}

\author{
Kristian Packalén \\ Turku Centre for Computer Science, \\ Institute for Advanced Management Systems \\ Research at Åbo Akademi University, FINLAND \\ kristian.packalen@abo.fi
}

\begin{abstract}
In an ICT $R \& D$ project in the Finnish archipelago, we have come in contact with 17 small business owners, and have gained hands-on information regarding some of the challenges they are facing and problems they have in their everyday work routines. We believe one solution for SMEs in similar settings is to start collaborating more, forming collaborative networks, enabling more effective information sharing, problem solving and also the creation of new value for their customers. The paper presents the challenges and proposes solutions, based on the situation we have observed but presumably also applicable to similar settings.
\end{abstract}

\section{INTRODUCTION}

Small and medium-sized enterprises (SME) represent $99 \%$ of all enterprises in the European Union (EU ICT Task Force Report, 2006). Consequently, they play an important role in the economy as well as in society, which is recognized by many authors (see e.g. Thurik and Wennekers, 2004). However, the small businesses often seem to remain small, not reaching their full development potential, recognized by Hadjimanolis (1999). The reason is e.g. limited resources, for example of expertise and money. Hadjimanolis further mention difficultness in answering customers' needs as a problem factor limiting the potentials of SMEs. Other problems facing SMEs in a larger extent than larger organisations is the amount of resources that is consumed by administrative tasks. In Finland this threshold is substantial especially if the SME wants to grow and hire new people, due to the current employment laws and regulations. Hence, much of the small business owners' time goes to administrative and bureaucratic work, leaving little or no time for developing the firm or innovating, i.e. being entrepreneurial in the sense of Schumpeter's (1912) definition of an entrepreneur.

Small businesses in the archipelago face additional challenges that their mainland colleagues and competitors usually do not. SMEs and entrepreneurs in the archipelago spend more resources at finding solutions to communication and logistics problems. Communication problems might exist between the businesses and their customers, in a worst case scenario leading to lost business opportunities. In addition to these aforementioned challenges, many of the SMEs in the 
archipelago are in the tourism industry, which is, according to Cabrini (2005), becoming more competitive as the tourists' needs are continuously changing. Today's tourists often want full service, with seamless activities, but are also willing to pay for it. The small businesses in the archipelago will need to adapt to these changes in demand, which might be quite difficult for small firms to handle by themselves.

In this paper, collaboration and the use of ICT is proposed, in order to help the small business owners in their endeavors of being entrepreneurial and fulfill the needs of their customers. We see building and participating in Virtual Collaborative Networks (VCN) as a promising solution.

\section{THE MobiReal PROJECT}

In the Fall 2007, the Institute for Advance Management Systems Research (IAMSR) at the Åbo Akademi University conducted an educational programme in 2 municipalities in the Finnish southwestern archipelago. The project, named MobiReal, was funded partly by the European Social Fund, ESF. The aim of MobiReal was to provide theoretical and especially practical knowledge about new information and communication technologies (ICT) for entrepreneurs and SMEs in the archipelago and also for the employees of the municipalities. Furthermore, the MobiReal project presented new business models for entrepreneurs and SMEs employing ICT solutions foremost within the tourism and hospitality industry. The idea was to demonstrate how ICT could be applied to create new business opportunities.

The general objective of the project was to show how useful services, improving the daily life of the entrepreneur and enabling things previously not possible with existing resources, can be developed using ICT. To measure when such a service has been accomplished, we use the Braudel rule, as presented by Keen and Mackintosh (2001): "changing the limits of the possible in the structure of everyday life". This rule can be seen as the guiding light of this paper.

During the project, we have gotten some insight into the everyday life of small business owners, and challenges they are facing. A small business in the archipelago often has some collaboration in place. However, based on the answers from the postproject questionnaires, we see that most small business owners would like to collaborate more with other companies. The question is then why this is not done in any larger extent, and what could be done to enable more collaboration and whether the collaboration effectively could take place in a virtual setting.

This paper discusses how technology can help small businesses and whether electronic collaboration could be accomplished. We believe technology in itself can be very beneficial for the SMEs, but that even more can be accomplished by the creation and participation in virtual collaborative networks (VCN). We discuss the first steps we have taken to creating such a virtual collaborative setting. Furthermore, we discuss a possible continuation of the learning and collaboration that has been initiated, that is, how the optimal collaborative network for small businesses could look like for SMEs in the archipelago but also more generally. 


\subsection{Research Objectives and Questions}

The research objectives related to collaborative networks for SMEs are based on the Braudel rule, and include finding viable methods by which SMEs can receive support in developing their businesses and find new business opportunities in a resource effective manner. Also, a research objective was to find alternative solutions to maintaining the collaboration between academics and the SMEs as well as internally among the SMEs.

The main research question in relation to these research objectives is:

Could Virtual Collaborative Networks help small business owners become more entrepreneurial?

\subsection{Research Methodology}

The action research model is chosen for the development, and consequent teaching, of the VCN. Action research is an iterative process, which should incorporate the views and needs of as many stakeholders as possible. Cummings (1989, p. 47) states that action research involves considerable collaboration between the change implementer and the stakeholders the change affects, and that data gathering and diagnosis before action planning and implementation is important, as well as the evaluation of results after the action has been taken. Both before and after the project, we conducted questionnaires, where we asked the participants to grade their computer literacy and also what collaborative tools they use. We aimed at adapting the project, based on these answers and also learn how to improve things based on the post-project questionnaires.

\section{COLLABORATIVE NETWORKS - OPPORTUNITIES AND CHALLENGES}

A possible answer to the needs and problems SMEs are facing, as we described in the introduction, is according to Taylor (2005) that the SMEs should collaborate with other organisations, by participating in strategic alliances, and then be able to utilize each other's resources and competencies. Recently, we have seen a wide variety of different terms emerging, aiming at explaining various forms of collaborative networks, as e.g. Value Network, Value Web, Virtual Organizations, Virtual Enterprises, Virtual Communities, Collaborative Virtual Laboratories, Communities of Practice, Communities of Interest, and so forth. Although these have some differences, we believe they generally explain quite similar phenomena, and we think it is wise to follow Camarinha-Matos and Afsarmanesh's (2005) recommendation of using the term collaborative network as an umbrella term for these phenomena. Camarinha-Matos and Afsarmanesh (2006) define a collaborative network as "a network consisting of a variety of entities (e.g. organizations and people) that are largely autonomous, geographically distributed, and heterogeneous in terms of their operating environment, culture, social capital and goals, but that 
collaborate to better achieve common or compatible goals, and whose interactions are supported by computer network."

\subsection{Opportunities with collaborative networks}

Collaboration is commonly seen as a key enabler of value creation and innovation (see e.g. Martinus et al. 2005). Communities consisting of people with different backgrounds and expertise offer great possibilities to enable innovation and solve problems. Metcalf's law applies, which states that the value of a network grows exponentially in relation to the number of members. This opportunity of gathering collective intelligence (see e.g. Paavola, Lipponen and Hakkarainen, 2002) should be utilized to get better information for example for decision making purposes, and to avoid double labour.

To enable collaboration, we propose building, and participating in, virtual collaborative networks. By virtual we mean that the community should exist on the Internet, being accessible using personal computers or handheld devices and enable electronic collaboration. Quereshi and Keen (2005) define electronic collaboration as "the purposeful use of networking and collaborative technologies to support groups in the creation of shared understanding".

The benefits of collaboration in a virtual setting include that more members can enter the network than is otherwise possible in a traditional off-line setting, that it allows greater disparity of members, enabling a multi-discipline setting, which in turn presumably enables better results. Also, more effective working methods and possibilities to save resources is one of the key opportunities as well as accomplishing economies of scale. When each member can focus on his or her core capabilities, resources can be shared (Camarinha-Matos and Afsarmanesh, 2006).

Zheng et al. (2003) claim that the Internet enables SMEs to benefit from the use of information and communication technology. The Internet presents an affordable and simple way to reach new customers and suppliers. The Internet also creates a global market for companies, but can also be a drawback since the competition is tightened for domestic or local companies. However, it seems that many SMEs do not use these opportunities to their full potential and we ask whether participating in virtual collaborative networks could improve this situation.

\subsection{Challenges when planning and implementing collaborative networks}

Quereshi and Keen (2005) claim that previous attempts to share knowledge both within and across organizations or entities have often failed. Rutkowski et al. (2002) show the problems that can occur in virtual collaboration, and that you have to take many aspects into mind when designing virtual collaborative environments; aspects regarding technology as well as social aspects. Cultural aspects also play an important role. Hagel and Armstrong (1997, p. 172) recognize that the members are the most important factor of a virtual community, and not the technology. Hence, the development and implementation of virtual communities is not only a technical issue, but rather an organisational one. As we include also virtual communities in our definition of CNs, this applies also in our setting.

To get the SMEs to use the virtual collaborative network, some change management methods will presumably be needed. These change management 
procedures include for example having good information and persons supporting and encouraging the usage, for example change agents and sponsors. The value of the community must be visible in order to attract users. To accomplish this, education of all stakeholders regarding the actual use and the possibilities should be done. We have given courses in the use of ICT to entrepreneurs in the archipelago, where we have introduced the idea of an electronic collaborative network. The SMEs responded very well to this idea. Whether a $\mathrm{CN}$ will appear will depend on a large number of factors, and will presumably entail changing the attitudes and work practices of the entrepreneurs. Information, education, and demonstration of good practices will presumably be needed of the potential members. These are closely related to factors generally seen as change management, which we believe can be adopted also to cases like the presented one. Also resources will be needed to develop the technical functions needed to enable the VCN.

Trust is generally seen as a key factor for accomplishing successful collaboration, especially in a virtual setting (Child, 2001, Rutkowski et al., 2002). The SMEs in the small municipalities studied generally already are collaborating, and know each other from before. It will, then, be interesting to see whether this affects the outcome of the virtual collaboration, and whether the existing relations easily can be transferred to a virtual setting or not. One factor that might be discouraging is that the SMEs we have been dealing with are quite unfamiliar with ICT, as we noticed during the MobiReal project. This may very well mean that virtual collaboration will become difficult to get started. To counter this, further education of the potential users is needed. Another possibility is that face to face collaboration is seen as better, or more easily accomplished. As long as collaboration is taking place, it does not matter in what form it takes, however we believe a virtual setting brings additional values.

\subsection{Technologies and Tools for enabling Virtual Collaborative Networks}

Lee et al. (2003) describes the existing tools that are used to help build the virtual community by supporting communication. These are for example e-mail, forums, message boards and chat-rooms. Forums are the most common tool used, according to the authors. Forums are used for debates going on for an extended period of time, with discussions regarding topics common to the participants. Chat-rooms enable quick communication, often with shorter messages, also often regarding some common topic. The difference between chat-rooms and forums is that the chats often take place in real time, and that the information entered is perishable. Other, less frequently used tools, are internet broadcasts, telephone-, and video conferencing. Lee et al. question whether these, aforementioned, simple tools really can support knowledge transfer among the participants.

When people talk about technology-mediated collaboration tools, they foremost seem to talk about e-mail, chats and forums. Two examples of this are to be found in the articles by Lee et al. (2002) and Rutkowski et al. (2002). However, wiki has risen as a very important tool for collaboration and a space for collective intelligence. Schaffert et al. (2006) claim that wikis can serve as a knowledge platform for a community of practice, where members of the community can share their knowledge and information with the group, work together or discuss issues. Schaffert et al. also state that a wiki can be used by new members of the community 
to get informed about the community and its practices. They furthermore regard wiki as a good technology for creating interdisciplinary and intercultural communication environments, where people from different backgrounds can be brought together and discuss a common topic. We believe that this is one of the most powerful features of wiki, and other virtual communication and collaboration means. By bringing together people with different backgrounds, knowledge that otherwise couldn't have been created can be created.

Wiki enables co-authoring of web-sites in a simple manner. It enables whomever to contribute, building a database of information based on the knowledge of a multicultural, cross-disciplinary group of people. Lee et al. (2002) claim that there is a lack of tools enabling true knowledge transfer and in-depth sharing among the participants. We believe that Wiki can be an important answer to this request. The strength of wiki compared to forum is the easiness of retrieving information from the knowledge source. For a forum to be effective, the participants often need to follow the forum continuously. Although there often are search functions in forums, it can be difficult to get the whole picture and receive all information regarding a specific topic, or get a general picture about the discussions. With a Wiki, on the other hand, information is usually stored in a way that enables a quick overview as well as helps the participants to get a more profound view of a specific topic.

It is important to stress that accessing the virtual collaborative network should be possible both using web-based and mobile technologies, as they each have their own strengths and weaknesses. Together, these technologies presumably could support the new working methods needed in the archipelago. People usually prefer a personal computer, if it is available, as a personal computer is easier, quicker and more comfortable to use. However, people are often on the move and do not have access to a desktop computer, which seems to apply especially to the people in the archipelago. Then, the ubiquitous nature of mobile devices is needed to allow virtual work on the move (Verburg and Bosch-Sijtsema, 2007).

The technologies used for creating the virtual collaborative network should be easy to use, i.e. be purposeful according to the needs of the users and have good usability, to attract usage rather than discourage it. As for example Davis (1989), with his technology acceptance model, has noticed, it doesn't matter how good a system is, if it is difficult to use. Hence, we aim at the simplicity of the systems. Further on, when collaboration is active, more advanced functions can be introduced upon the users' request.

Even though the technologies used for the creation of virtual collaborative networks are important to study, we believe the challenges when developing the solutions will not as much concern technological issues as organisational and social ones as well as reaching systems with great usability and good content. The value of the content and the functions of the developed products must be apparent to all potential users so that the collaborative network gets enough users and a critical user mass will be reached. If enough users are reached, the community will be living and user-generated content will be developed. This presumably frees up resources and more, better information can be created when the users are enabled to create the content.

Generally speaking, collective intelligence could be gathered through technology enabling user-generated content, and stored in a knowledge repository for later use and revision. Such a knowledge repository is an important part of a VCN. 
Information in such a knowledge repository could for example be good practices. The knowledge repository could be built upon wiki-technology, enabling simple coauthoring of information. Tobin (1997) states that knowledge repositories can be used only to capture explicit knowledge but that electronic forums can be used to uncover tacit knowledge. We do not want to go into whether tacit knowledge really can be captured or not, in any case forums are an important part in a virtual collaborative setting.

\subsection{Change Management}

As is recognized by many authors and practitioners of collaborative networks, accomplishing a working $\mathrm{CN}$ is not easy. We have not yet found a solution that would answer this question to its full extent, but believe change management could play an important role in facilitating the function of a $\mathrm{CN}$, especially in the initial phase. We believe this applies to all organizations planning a participation in a $\mathrm{CN}$, also SMEs.

The research methodology of action research that we have used in this case also function as a change management method according to Cummings (1989, p. 47). The action research model is an iterative development process, where collaboration between the change implementers and those that the change affects is vital. Good information flow, as well as input of those affected by the changes, are important features of many change management methods, which we believe is incorporated in the action research model.

\section{PROPOSAL: DEVELOPING A COLLABORATIVE NETWORK FOR SMES IN THE SERVICE SECTOR IN THE FINNISH ARCHIPELAGO.}

Merging collaboration with digital technologies should result in a basis for a virtual organisation. Especially smaller businesses are expected to gain from the use of ICT by developing and participating in a virtual organization. Knowing that small businesses as a rule have limited resources, ICT can be a relatively inexpensive way to create the basis for a $\mathrm{CN}$ and receive many of the advantages that otherwise only larger organisations have. Examples of such advantages are found in marketing, distribution and sales (Botkin and Matthews, 1992, p. 33). We believe that smaller organisations can become more efficient by using ICT and CNs. Thus small businesses will be able to solve many easy problems, dull or time-consuming routine tasks and instead be able to focus on more important, entrepreneurial activities, but also benefit from many of the advantages larger organisations have, for example accomplishing economies of scale.

The planned collaborative network should function as a knowledge repository, harnessing the power of the users and getting network effects. However, we do not yet know how this could be accomplished. It will not be an easy task. As recognized by for instance Hagel and Armstrong (1997, pp. 132-133) and Tickle et al. (2007), building a virtual community is not easy. 
A web-based portal will be the core of the planned initial VCN, and will be accessible primarily via personal computers, but also via mobile devices as this is seen important from a tourism perspective. The idea of developing a portal was born in the general lectures held within the MobiReal project, during a discussion and brainstorming session between us, the lecturers, and the participating small business owners. The discussion regarded how the collaboration between the IAMSR and the SMEs could continue also after the end of the project. Also, the idea that the SMEs should start collaborating more with each other electronically emerged. We proposed that an Internet portal could be constructed by the IAMSR in cooperation with some of the participating SMEs. Initially, the portal should have some simple functions, due to the limited scope of the MobiReal project, but also to let the SMEs get familiar with virtual collaboration. The initial functions of the portal include: a knowledge repository, discussion forum, profile pages, document database and groups. The knowledge repository could presumably be based on a wiki, where the participants can co-author for example lessons learned during the project, best practices of the industries, general tips and tricks related to entrepreneurship, etc. The discussion forum is of a traditional type found in almost every virtual community. The profile pages allow for easy presentation of the SMEs, and can function as a substitute for the SMEs' own web-site. The document database, which in the beginning was related to the MobiReal project, can be used to share documents. The groups can be used to have closed virtual communication and collaboration. Additionally, the portal can function as a marketing place for products, presumably web-based, that are related to the archipelago. We hope that such a portal would be used by the SMEs to collaborate and also act as a common face for the small businesses towards their customers, and be an easy way for the SMEs to market themselves and for the potential customers to see the services offered in the two municipalities. The entrepreneurs should take part in the development, and take over the prototype and continue to develop it. This presumably makes them more motivated, plus that they learn how it works from the beginning, which we believe is in the essence of the action research model. However, this takes some resources, since the entrepreneurs need to be educated in the technological aspects of the $\mathrm{VCN}$, in order to maintain it and continue developing it. This knowledge transfer is as important as the actual transfer of a product. Instead of being a one-time event, the knowledge transfer can continue to benefit them in the future. Also, this is vital from a resource perspective as the resources usually are scarce for academics. Furthermore, this may also provide a potential revenue source for the entrepreneurs in the future.

Generally speaking, we would like to see that the collaborative network will have a positive effect on the development of new business opportunities by promoting entrepreneurship and helping individuals in their quest to become entrepreneurs.

The objectives of the planned collaborative network include:

i) Working as a collaboration platform between SMEs in the service industry, primarily in the Finnish south-western archipelago

ii) Acting as a common communication channel between the SMEs and their (potential) customers 
iii) Functioning as a collaboration channel between SMEs and external partners, e.g. academics

\section{CONCLUSION}

We believe that the use of new technologies by the entrepreneurs in the archipelago and more collaboration with other entrepreneurs and with other sectors and organisations would benefit the everyday life in such a degree that they could spend more time to develop their business. We consider developing and participating in virtual collaborative networks, engaging in one form of a virtual organisation, to be a lucrative opportunity for the small business owners. Presumably, collaboration is the only realistic way to tackle many of the challenges these small businesses are facing. During the project in the archipelago, we have seen the need for improved collaboration tools that apply a variety of new technologies. However, due to the limited scope and resources of the project, we have so far only been able to develop applications with limited capabilities.

We recognize that accomplishing a working Virtual Collaborative Network is a difficult task, where technology, although important, only plays a minor role. Hence, accomplishing pervasive collaborative networks requires both persistency, good change management, and a great portion of luck.

Virtual Collaborative Networks offer great possibilities for improved work and communication. Economies of scale can be accomplished when double labour is reduced, and existing information is used more efficiently. The collective intelligence of the members of the community can enable new and better knowledge to be created. The development of virtual collaborative networks should be based on the needs of the users, rather than on technological finesses. If done correctly, the presumed outcomes will provide a substantial value for all stakeholder groups.

\section{REFERENCES}

1. Botkin, J., Matthews, J. Winning Combinations The Coming Wave of Entrepreneurial Partnerships Between Large \& Small Companies, John Wiley \& Sons, 1992

2. Cabrini, L. Tourism in the World. A vision for the future, 2nd Congress of Tourism - "To reinvent Tourism, To affirm Portugal", Estoril, Portugal, 4 and 5 July 2005

3. Camarinha-Matos, L. \& Afsarmanesh, H. Collaborative networks: a new scientific discipline, Journal of Intelligent Manufacturing, 16, 439-452, 2005

4. Camarinha-Matos, L. and Afsarmanesh, H. Collaborative Networks, Value creation in a knowledge society, In Proceedings of PROLAMAT'06 (Springer), Shanghai, China, 14-16 Jun 2006

5. Child, J. Trust - The Fundamental Bond in Global Collaboration, Organizational Dynamics, Vol. 29, No. 4, pp. 274-288, 2001

6. Cummings, T. Huse, E. Organization Development and Change. Fourth Edition, St. Paul: West Publishing Company, 1989

7. Davis, F. Perceived Usefulness, Perceived Ease of Use and User Acceptance of Information Technology, MIS Quarterly, Vol. 13, No. 3, pp. 319-339, 1989

8. EU ICT Task Force Report, Fostering the Competitiveness of Europe's ICT Industry, 2006

9. Hadjimanolis, A. Barriers to innovation for SMEs in a small less developed country (Cyprus), Technovation 19, 561-570, 1999

10. Hagel, J., Armstrong, A. Net Gain: Expanding Markets through Virtual Communities, Boston, Harvard Business School Press, 1997 
11. Keen, P., Mackintosh, R. The Freedom Economy, Gaining the mCommerce edge in the Era of the Wireless Internet, Osborne/McGraw-Hill, 2001

12. Lee, F., Vogel, D., Limayem, M. Virtual Community Informatics: What We Know and What We Need to Know, appearing in Proceedings of the $35^{\text {th }}$ Hawaii International Conference on System Sciences, pp. 2863- 2872, 2002

13. Lee, F., Vogel, D., Limayem, M. Virtual community informatics: A review and research agenda, Journal of Information Technology Theory and Application, pp. 47 - 61, 2003

14. Martinus, K., Rowe, M., Burn, J., Walker, E. Beyond Clusters - Collaborative Commerce and Clustering, CRIC Cluster conference, Beyond Cluster - Current Practices \& Future Strategies, Ballarat, June 30 - July 1, 2005

15. Paavola, S., Lipponen, L., Hakkarainen, K. Epistemological Foundations for CSCL: A comparison of three modes of innovative knowledge communities, In G. Stahl, (ed.), $4^{\text {th }}$ Computer Support for Collaborative Learning: Foundations for a CSCL Community, (CSCL-2002), Boulder, Colorado, pp. 24-32, January 2002

16. Quereshi, S., Keen, P. Organizational Transformation by Activating Knowledge: The Mediating role of Collaboration Technologies, Institute for Advanced Management Systems Research, Research Report 5, 2005

17. Rutkowski, A., Vogel, D., Van Genuchten, M., Bemelmans, T., Favier, M. E-Collaboration: The Reality of Virtuality, IEEE Transactions on Professional Communication, Vol. 45, No. 4, December 2002

18. Schaffert, S., Bischof, D., Bürger, T., Gruber, A., Hilzensauer, W., Schaffert, S. Learning with Semantic Wikis, In: First Workshop SemWiki2006 - From Wiki to Semantics", co-located with the 3rd Annual European Semantic Web Conference (ESWC), Budva, Montenegro, 11th - 14th June, 2006

19. Schumpeter, J., The Theory of Economic Development, Oxford University Press, 1912

20. Taylor, A. An Operations Perspective on Strategic Alliance Success Factors, International Journal of Operations and Production Management (25:5), 2005, pp. 469-490.

21. Thurik, R., Wennekers, S. Entrepreneurship, small business and economic growth, Journal of Small Business and Enterprise Development, Vol. 11, No. 1, pp. 140-149, 2004

22. Tickle, M., Michaelides, R., Kehoe, D. The Challenge of Creating Virtual Communities, Proceedings of the 18:th Information Resources Management Association (IRMA), 19-23 May, 2007

23. Tobin, D. The Knowledge-Enabled Organisation - Moving From "Training" to "Learning" to Meet Business Goals, American Management Association, 1997

24. Verburg, R., Bosch-Sijtsema, P. Guest Editorial - The Limits of Virtual Work, The Electronic Journal for Virtual Organizations and Networks, Vol. 9, Special Issue "The Limits of Virtual Work", July, 2007

25. Zhang, D., Zhao L., Zhou, L., Nunamaker, J. Can e-learning replace classroom learning? Communications of the ACM, 47 (5), pp. 75-78, 2004 